\title{
What Is the Important Point Related to Follow-Up Sonographic Evaluation for the Developmental Dysplasia of the Hip?
}
M. M. Donma ${ }^{1}$
M. Dogru ${ }^{2}$
M. Demirkol ${ }^{1}$
O. Ozcaglayan ${ }^{2}$
B. Topcu ${ }^{3}$
T. I. K. Ozcaglayan ${ }^{2}$
K. A. Gonen ${ }^{2}$
B. Nalbantoglu ${ }^{1}$
A. Nalbantoglu ${ }^{1}$
R. Dogru ${ }^{2}$
H. Ulucan ${ }^{2}$
O. Karakoyun ${ }^{4}$
M. F. Erol ${ }^{4}$
A. Y. Guzelant ${ }^{5}$
O. Donma ${ }^{6}$

${ }^{1}$ Department of Pediatrics, Medical Faculty, Namik Kemal University, Tekirdag, Turkey

2 Department of Radiology, Medical Faculty, Namik Kemal University,

Address for correspondence M. M. Donma, PhD, Department of Pediatrics, Medical Faculty, Namik Kemal University, Tekirdag,

Tekirdag, Turkey

${ }^{3}$ Department of Biostatistics, Medical Faculty, Namik Kemal

University, Tekirdag, Turkey

${ }^{4}$ Department of Orthopedics and Traumatology, Medical Faculty, Namik Kemal University, Tekirdag, Turkey

${ }^{5}$ Department of Physical Medicine and Rehabilitation, Medical

Faculty, Namik Kemal University, Tekirdag, Turkey

${ }^{6}$ Department of English Faculty of Medicine, Cerrahpasa Medical

Faculty, Istanbul University, Istanbul, Turkey

Turkey (e-mail: mdonma@gmail.com).

J Child Sci 2017;7:e123-e126.

\begin{abstract}
Keywords

- developmental dysplasia of the hip

- sonography

- follow-up examination

Developmental dysplasia of the hip (DDH) is an important cause of childhood disability. Subluxation or dislocation can be diagnosed through pediatric physical examination; nevertheless, the ultrasonographic examination is necessary in diagnosing certain borderline cases. It has been evaluated routine sonographic examination of 2,444 hips of 1,222 babies to determine differences in both, developmental dysplasia and types of hips, and evaluated their development on the 3-month follow-up. Evaluating the pathologic " $\alpha$ " angles under 59, there was no statistically significant differences between girls and boys in both right (55.57 \pm 3.73$)(56.20 \pm 4.01),(p=0.480)$, and left $(55.79 \pm 3.96)(57.00 \pm 3.84)$, $(p=0.160)$ hips on the 45 th day of life. Routine sonographic examinations on the 45th day of life revealed that 51 of (66.2\%) 77 type 2a right hips were girls and 26 (33.8\%) were boys. The number of the right hips that develop into type 1 was 38 (74.5\%) for girls and 26 (100\%) for boys on the 90 th day of life $(p=0.005)$. A total of 87 type 2a left hips included 64 girls (73.6\%) and 23 boys (26.4\%). In the 90th day control, 49 right hip of girls (76.6\%) and 21 right hip of boys $(91.3 \%)$ developed into type $1(p=0.126)$. In the assessment of both left and right hips, girls showed a significantly higher frequency in latency and boys showed significantly higher development in the control sonography. A total of 31 girls $(2.5 \%)$ and 11 boys $(0.9 \%)$ accounted for a total of $42(3.4 \%)$ cases who showed bilateral type 2a hips in 1,222 infants. On the 90 th day control, 26 girls ( $83.9 \%$ ) and all 11 boys ( $100 \%$ ) developed into type $1(p=0.156)$. The study emphasizes the importance of the sonographic examination on the 90th day of life. Results of the investigation include the data of sonographic screening of DDH on the 45th day, and also stress the importance of the 90th-day control sonography after a close follow-up with physical examination between 45th and 90th days of life.
\end{abstract}

received

May 2, 2017

accepted after revision

August 16, 2017
DOI https://doi.org/

10.1055/s-0037-1606611. ISSN 2474-5871.
Copyright $\odot 2017$ Georg Thieme

Verlag KG Stuttgart · New York
License terms

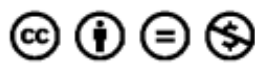




\section{Introduction}

Developmental dysplasia of the hip (DDH), one of the most common musculoskeletal disorders in infants, may have serious sequela and complications, which can be prevented with early diagnosis, timely and appropriate actions. Incidence can be detected in higher ratios with ultrasonographic examination than the clinical examination., ${ }^{1,2}$

Because there are significant differences between cases with the diagnosis of DDH, follow-up should be made with a careful approach. ${ }^{3,4}$ In our study, we aim to evaluate routine sonographic examination of 2,444 hips of 1,222 babies for differences in both genders and types of hips, and evaluated their development on the 3-month follow-up.

\section{Patients and Methods}

The study includes routine bilateral hip ultrasound screening of 1,222 infants who were referred to the Namik Kemal University, Faculty of Medicine, Department of Radiology, Ultrasound Unit by the Department of Pediatrics between June 2009 and September 2013.

Routine bilateral hip ultrasound screening was performed in infants on the 45 th day \pm 7 days of life. Aplio XG Toshiba Medical Systems, 2009, Japan, the ultrasound device and 6 to $12 \mathrm{MHz}$ linear probe were used in the examinations, by radiologists who are experienced in musculoskeletal system radiology. Technically, hip ultrasonography was made in lateral decubitus position of the baby, with the semiflexion of the hip and knee and lying with 15 to 20 degrees of internal rotation.

Hip ultrasonographic typing of the Graf method is made with measurement of " $\alpha$ " angle, and also the overall morphology of the hip and the relationship between femoral head and acetabulum are evaluated. According to the Graf method, " $\alpha$ " angle is defined as the angle between the base line drawn a parallel with the lateral edge of the iliac bone and the line from the ossified end of the ilium to the $Y$ cartilage of acetabulum.

The evaluation is made according to the " $\alpha$ " angle, and " $\alpha$ " angle over 60 degrees is compatible with type 1 mature hip according to the Graf method (-Fig. 1). The " $\alpha$ " angle between 59 and 50 degrees is classified as type $2 a$, which is the physiological immaturity of infants under the age of 3 months while it is classified as type $2 b$; if the infant is older than 3 months. The " $\alpha$ " angle between 49 and 43 degrees is recognized as critical, unstable hip that is type $2 c$. The " $\alpha$ " angle less than 43 degrees is evaluated as type 3 that is dislocated to bony roof through cranial direction, and " $\alpha$ " angle less than 43 degrees is evaluated as type 4 that is severe dysplasia through caudal direction. ${ }^{5-7}$

Type 2a hips in routine controls were reassessed at 3 months of age and then control ultrasound was obtained. Type 3 and type 4 hips in routine controls in the first 4 to 6 weeks of life and type $2 \mathrm{~b}$ hips after 3 months of life were referred to the orthopedics and traumatology clinic, to prescribe the necessary treatment. Type 1 hips in the routine controls and type $2 \mathrm{a}$ hips that develop into type 1 hips at the

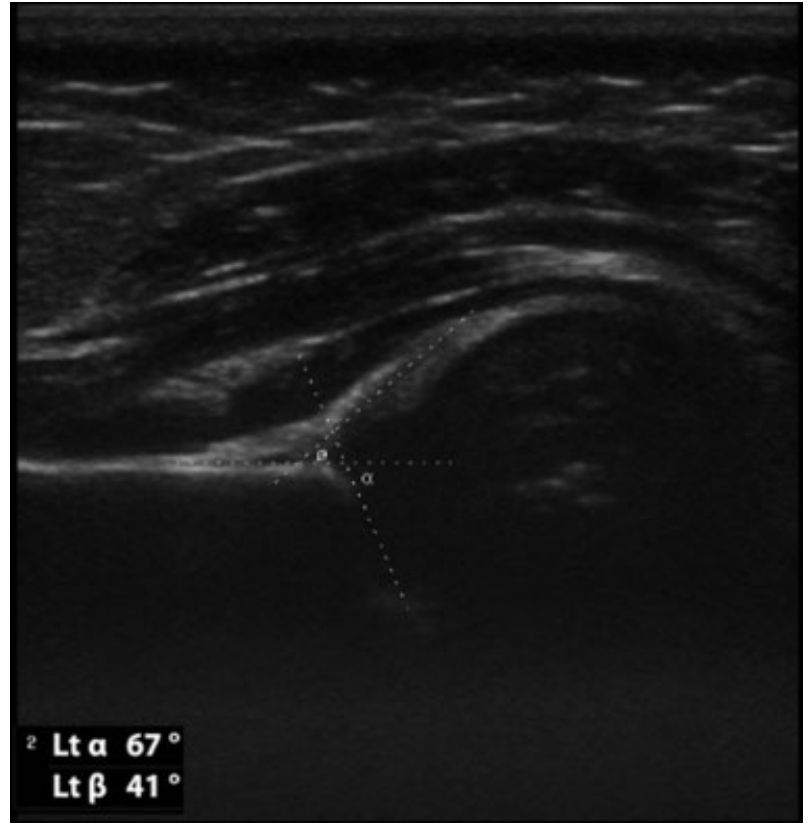

Fig. 1 A hip sonography shows the type 1 hip. The $\alpha$ angle is greater than 60 degrees, and the $\beta$ angle is less than 45 degrees.

third-month control were evaluated as normal and were given up to follow-up.

\section{Findings and Results}

The " $\alpha$ " angles were measured for both sexes in 1,222 infants in routine sonographic controls on their 45th day of life (-Figs. 2-5). Routine (45th day \pm 7 days) and follow-up (90th-day \pm 7 days) ultrasonographic typing (type 2a, 1 , and $2 \mathrm{~b}$ ) and remission rates for unilateral ( - Table $\mathbf{1}$ ) and bilateral (-Table 2) DDH cases.

A total of 1,222 infants on their 45th postnatal age were included in the study, and patients were followed up until the 90th postnatal day. Girls $(n=674)$ /boys $(n=548)$ ratio was found to be 1.23. Mean right " $\alpha$ " angle was $64.00 \pm 4.87$ for girls, and $65.05 \pm 5.07$ for boys $(p=0.000)$ on the 45 th day.

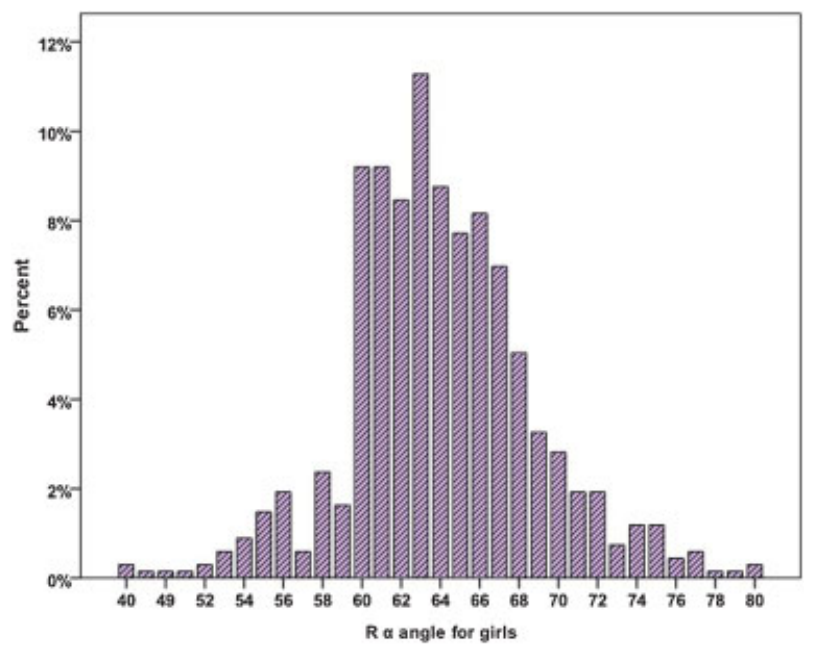

Fig. 2 Distribution of right " $\alpha$ " angles for girls. 


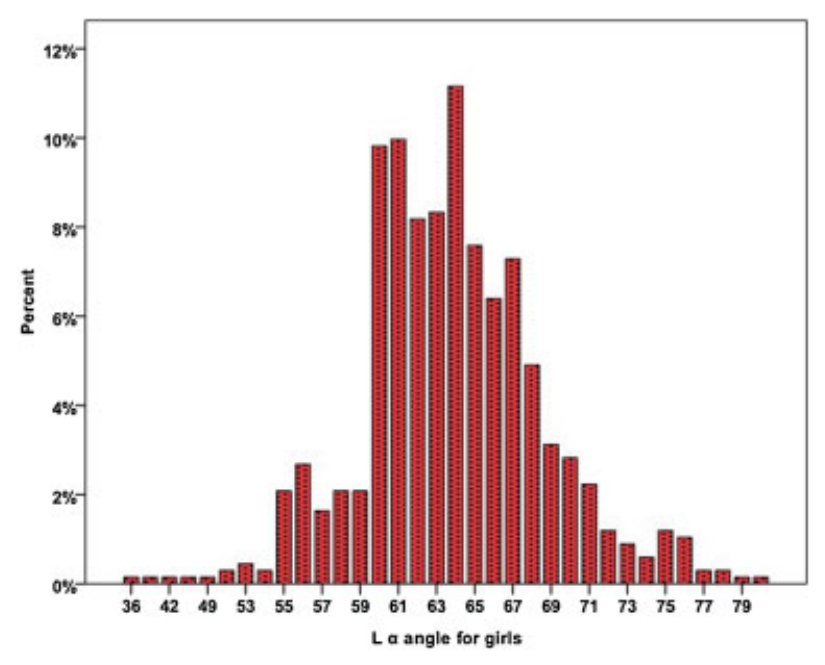

Fig. 3 Distribution of left " $\alpha$ " angles for girls.

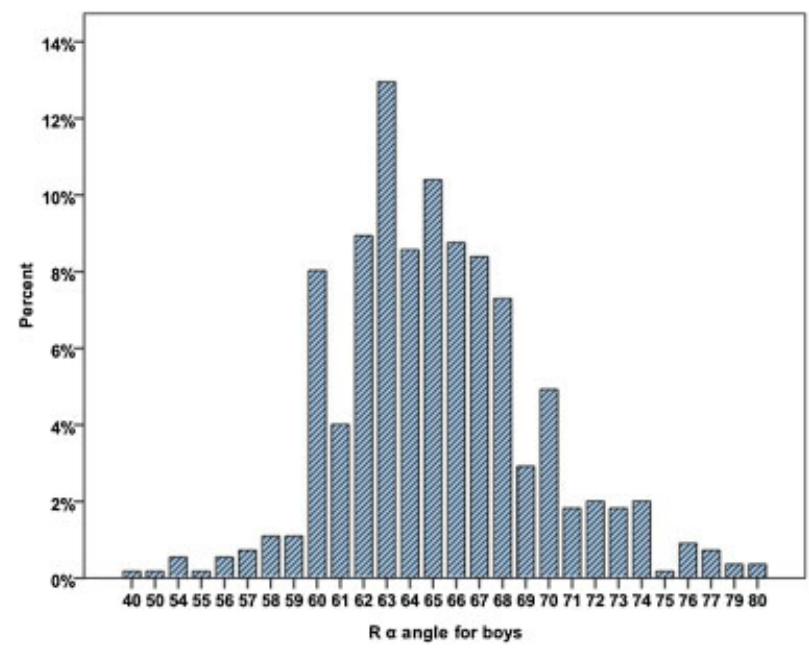

Fig. 4 Distribution of right " $\alpha$ " angles for boys.

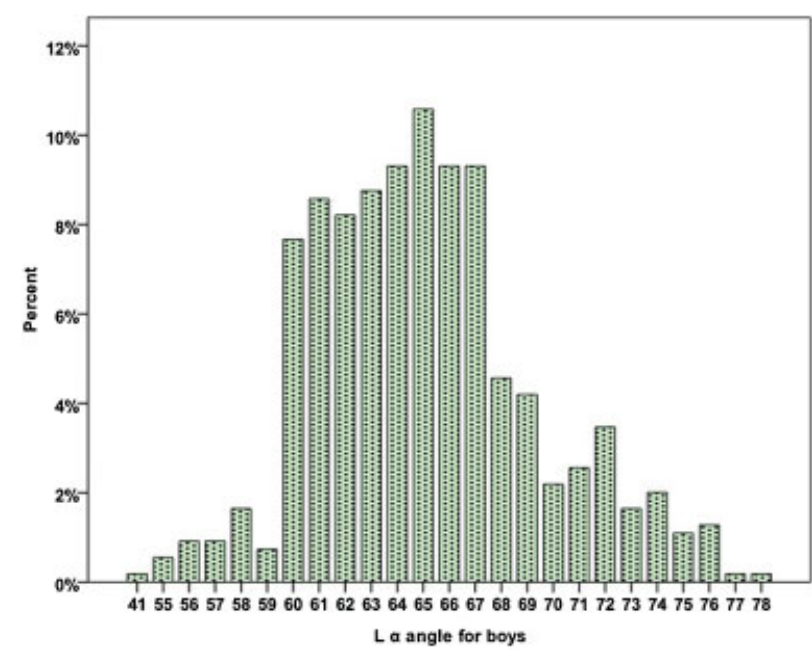

Fig. 5 Distribution of left " $\alpha$ " angles for boys.
Table 1 Routine and follow-up ultrasonographic typing and remission rates for unilateral developmental dysplasia of the hip cases

\begin{tabular}{|l|l|l|l|l|}
\hline \multirow{2}{*}{$\begin{array}{l}\text { Unilateral } \\
\text { hip }\end{array}$} & 45th day & \multicolumn{2}{|l|}{ 90th day } & \multirow{2}{*}{$p$ Value } \\
\cline { 2 - 4 } & Type 2a (\%) & Type 1 (\%) & Type 2b (\%) & \\
\hline$R \alpha_{\text {girl }}$ & $51(66.2 \%)$ & $38(74.5 \%)$ & $13(25.5 \%)$ & \multirow{2}{*}{0.005} \\
\hline$R \alpha_{\text {boy }}$ & $26(33.8 \%)$ & $26(100.0 \%)$ & $-(0.0 \%)$ & \\
\hline$R \alpha_{\text {total }}$ & 77 & 64 & 13 & \\
\hline$L \alpha_{\text {girl }}$ & $64(73.6 \%)$ & $49(76.6 \%)$ & $15(23.4 \%)$ & \multirow{2}{*}{0.126} \\
\hline$L \alpha_{\text {boy }}$ & $23(26.4 \%)$ & $21(91.3 \%)$ & $2(8.7 \%)$ & \\
\hline$L \alpha_{\text {total }}$ & 87 & 70 & 17 & \\
\hline$R+L \alpha_{\text {total }}$ & 164 & 134 & 30 & \\
\hline
\end{tabular}

Abbreviations: L, left; R, right.

Table 2 Routine and follow-up ultrasonographic typing and remission rates for bilateral developmental dysplasia of the hip cases

\begin{tabular}{|l|l|l|l|l|}
\hline \multirow{2}{*}{$\begin{array}{l}\text { Bilateral } \\
\text { hip }\end{array}$} & 45th day & \multicolumn{2}{|l|}{ 90th day } & \multirow{2}{*}{$p$ Value } \\
\cline { 2 - 4 } & $\begin{array}{l}\text { Type 2a } \\
(\%)\end{array}$ & $\begin{array}{l}\text { Type 1 } \\
(\%)\end{array}$ & $\begin{array}{l}\text { Type 2b } \\
(\%)\end{array}$ & \\
\hline$R+L \alpha_{\text {girl }}$ & $31(73.8 \%)$ & $26(83.9 \%)$ & $5(16.1 \%)$ & \multirow{2}{*}{0.156} \\
\hline$R+L \alpha_{\text {boy }}$ & $11(26.2 \%)$ & $11(100.0 \%)$ & $-(0.0 \%)$ & \\
\hline$R+L \alpha_{\text {total }}$ & 42 & 37 & 5 & \\
\hline
\end{tabular}

Abbreviations: L, left; R, right.

Mean left " $\alpha$ " angle measurement was $63.76 \pm 4.98$ for girls, and $65.04 \pm 4.37$ for boys $(p=0.000)$.

Evaluating the pathologic " $\alpha$ " angles less than 59 degrees, there was no statistically significant difference between girls and boys in both right $(55.57 \pm 3.73)(56.20 \pm 4.01),(p=0.480)$, and left $(55.79 \pm 3.96)(57.00 \pm 3.84),(p=0.160)$ hips.

However, when we evaluated the girls and boys in terms of the number of cases with pathological " $\alpha$ " angles less than 59 degrees, ratios of (7.6\%) and (4.7\%) for right hips and (9.5\%) and (4.2\%) for left hips, it showed a significant difference. These values were consistent with the results that DDH is seen in girls more than boys.

Routine sonographic examinations on the 45th day of life revealed that 51 of (66.2\%) 77 type 2a right hips were girls and $26(33.8 \%)$ were boys. The number of the right hips that develop into type 1 were 38 (74.5\%) for girls and $26(100 \%)$ for boys on the 90th day of life $(p=0.005)$.

A total of 87 type 2a left hips included 64 girls (73.6\%) and 23 boys (26.4\%). On the 90th day control, 49 right hip of girls (76.6\%) and 21 right hip of boys (91.3\%) developed into type 1 $(p=0.126)$. In the assessment of both left and right hips, girls showed a significantly higher frequency in latency and boys showed significantly higher development in the control sonography.

A total of 31 girls (2.5\%) and 11 boys ( $0.9 \%$ ) accounted for a total of 42 (3.4\%) cases showed bilateral type 2a hips in 1,222 infants. On the 90th day control, 26 girls (83.9\%) and all 11 boys (100\%) developed into type $1(p=0.156)$. 
Regardless of the gender differences, 164 unilateral (6.7\%) and 42 bilateral (3.4\%) accounted for a total of 206 cases (16.8\%) were type $2 \mathrm{a}$ on the 45 th day routine sonography; 30 unilateral $(1.2 \%)$ and 5 bilateral $(0.4 \%)$ accounted for a total of 35 (2.9\%) cases were type $2 \mathrm{~b}$ on the 90th day control sonography. The frequencies of right, left, and bilateral DDH were found quite significantly higher in girls than boys.

Our study highlighted the higher incidence of both unilateral and bilateral DDH in girls on the 45th-day routine sonography and after early conservative measures and approaches, detection of the significant reduction in the incidence in both sexes in the 90th-day control sonogram, and also lower recovery rate of girls than boys.

\section{Statistical Analyses}

PASW Statistics 18 for Windows statistical package program (SPSS Inc.) was used in analyses of the data. Findings determined in tables and figures.

The chi-square test was used for comparison of categorical variables. The $p$ value of $<0.05$ was accepted as statistically significant.

\section{Discussion}

Starting from the prenatal ultrasound examinations, ultrasonography is an important radiologic diagnostic tool in patients of all age for clinicians. ${ }^{8}$ DDH is an important cause of childhood disability. The pediatric examination can diagnose subluxation. Nevertheless, the ultrasonographic approach is necessary for borderline cases. ${ }^{9}$ DDH frequency can be detected at a much higher rate by ultrasonographic examination than the pediatric physical examination.

Only using the " $\alpha$ " in the evaluation of sonography performed as early as the second week after birth revealed that female gender is a significant risk factor, and the incidence is quite low for both the sexes. ${ }^{1}$ In many of the studies that examined the various factors stated, that the female gender is one of the most important risk factors. ${ }^{10,11}$

The studies highlighting the early diagnosis and treatment to avoid late complications reported the incidence of hip instability in newborns as 1 to $2 \% .^{12,13}$ Despite newborn screening and early treatment approaches, as a rare event, DDH may be encountered in older children particularly in developing countries. ${ }^{14,15}$ In such late unilateral or bilateral cases, conservative approach is not recommended, and direct surgical interventions are emphasized as a necessity. ${ }^{16}$

In studies examining the demographic characteristics of $\mathrm{DDH}$, female gender has been reported as a risk factor. ${ }^{17,18}$ Unstable, dysplastic hips may not only be easily diagnosed by clinical examination, but ultrasound evaluations have also been reported to detect DDH in the incidence rate of 2.5 to $4.7 \%^{1,3}$

The results of our research comply with the current literature in terms of both incidence and female gender domination. Our study emphasizes the importance of the sonographic examination on the 90th day of life. Results of our study include the data of sonographic screening of DDH on the 45th day, and also stress the importance of the 90thday control sonography after a close follow-up with physical examination between 45th and 90th days of life.

Conflict of Interest

None.

\section{References}

1 Kolb A, Schweiger N, Mailath-Pokorny M, et al. Low incidence of early developmental dysplasia of the hip in universal ultrasonographic screening of newborns: analysis and evaluation of risk factors. Int Orthop 2016;40(01):123-127

2 Dorn U, Neumann D. Ultrasound for screening developmental dysplasia of the hip: a European perspective. Curr Opin Pediatr 2005;17(01):30-33

3 Dogruel H, Atalar H, Yavuz OY, Sayli U. Clinical examination versus ultrasonography in detecting developmental dysplasia of the hip. Int Orthop 2008;32(03):415-419

4 Lehmann HP, Hinton R, Morello P, Santoli J. Developmental dysplasia of the hip practice guideline: technical report. Committee on Quality Improvement, and Subcommittee on Developmental Dysplasia of the Hip. Pediatrics 2000;105(04):E57

5 Graf R. New possibilities for the diagnosis of congenital hip joint dislocation by ultrasonography. J Pediatr Orthop 1983;3(03): 354-359

6 Graf R, Aksu M, Farkas P, Lercher K, Tschauner C. Kalça ultrasonografisi el kitabı. Istanbul, Turkey: AVRUPA Tip Kitapçilik Ltd.; 2011:14-20

7 Graf R. Ultrasonography-guided therapy [in German]. Orthopade 1997;26(01):33-42

8 Donma MM, Donma O, Sonmez S. Prediction of birth weight by ultrasound in Turkish population. Which formula should be used in Turkey to estimate fetal weight? Ultrasound Med Biol 2005;31 (12):1577-1581

9 Dezateux C, Rosendahl K. Developmental dysplasia of the hip. Lancet 2007;369(9572):1541-1552

10 Ortiz-Neira CL, Paolucci EO, Donnon T. A meta-analysis of common risk factors associated with the diagnosis of developmental dysplasia of the hip in newborns. Eur J Radiol 2012;81(03):e344-e351

11 Bache CE, Clegg J, Herron M. Risk factors for developmental dysplasia of the hip: ultrasonographic findings in the neonatal period. J Pediatr Orthop B 2002;11(03):212-218

12 Laborie LB, Markestad TJ, Davidsen H, et al. Selective ultrasound screening for developmental hip dysplasia: effect on management and late detected cases. A prospective survey during 1991-2006. Pediatr Radiol 2014;44(04):410-424

13 Shipman SA, Helfand M, Moyer VA, Yawn BP. Screening for developmental dysplasia of the hip: a systematic literature review for the US Preventive Services Task Force. Pediatrics 2006;117(03): e557-e576

14 Sewell MD, Eastwood DM. Screening and treatment in developmental dysplasia of the hip-where do we go from here? Int Orthop 2011;35(09):1359-1367

15 Sibiński M, Adamczyk E, Higgs ZC, Synder M. Hip joint development in children with type IIb developmental dysplasia. Int Orthop 2012;36(06):1243-1246

16 Agus H, Bozoglan M, Kalenderer Ö, Kazımoğlu C, Onvural B, Akan İ. How are outcomes affected by performing a one-stage combined procedure simultaneously in bilateral developmental hip dysplasia? Int Orthop 2014;38(06):1219-1224

17 Loder RT, Shafer C. The demographics of developmental hip dysplasia in the Midwestern United States (Indiana). J Child Orthop 2015;9(01):93-98

18 Orak MM, Karaman O, Gursoy T, Cagirmaz T, Oltulu I, Muratli HH. Effect of increase in birth weight in a newborn on hip ultrasonography. J Pediatr Orthop B 2015;24(06):507-510 